\title{
Discussion-oriented Teaching Reform on Digital Electronic Technology Course
}

\author{
Min Lin ${ }^{a}$, Li Wang ${ }^{b}$ \\ Shanghai Medical Instrumentation College, University of Shanghai Science \& Technology, \\ Shanghai, 200093, China \\ aemail: Luc77sna@163.com, bemail: wangl@163.com
}

\begin{abstract}
Keywords: Digital Electronic Technology; discussion-oriented teaching; question situation; teaching reform
\end{abstract}

\begin{abstract}
The course of Digital Electronic Technology integrates the theory and its application. In the traditional teaching mode, students passively receive knowledge and do some exercises. In order to improve students' initiative, we explored to teach the course in the discussion-oriented mode. On the basis of introducing the course design idea, this paper involves four question situations to illustrate the context arrangement during the discussion teaching. The implementation results show that the discussion teaching mode challenges teachers to have comprehensive abilities, but it can inspire students to study actively.
\end{abstract}

\section{Introduction}

Today is the age of information explosion; all kinds of new technologies emerge in an endless stream and develop rapidly. It is impossible for teachers to pass on infinite knowledge to students in the finite classes. Therefore, we should develop students to study more actively and to own excellent self-study ability and life education idea. It should be the goal for modern vocational education.

\section{Design Idea of the Course}

Discussion-oriented teaching mode adopts multiple teaching methods to develop students' selfstudy ability [1]. This mode is first proposed by Professor Guo [2].

In the traditional teaching mode, it emphasizes on teachers' teaching activities, but neglects students' learning experience. Students learn through the procedures of understanding, memorizing, repeating and reproducing the knowledge. This mode can't develop students' abilities of thinking and innovation. While in the discussion-oriented teaching mode, students play leading roles. Teachers provide the detailed question situation, then enlighten and encourage students to discuss every possible solution. Subsequently, students are divided into different groups. They are asked to solve the question in practice. During the practice, if students meet a new question, the teacher will enlighten and guide them to discuss again until they decide the solution scheme; then the group practices again..... the process circles until the question situation is solved in the end.

\section{Implement of Discussion-oriented Teaching}

Combining with the development trends of modern digital electronic technology, we try to construct the new arrangement of the teaching chapters according to the actual question situations instead of the traditional theory system. On the basis of following students' cognitive characteristic, we organize teaching contexts in 64 class hours from simplicity to complexity (see TABLE I). 
TABLE I.

ARRANGEMENT OF THE TEACHING CONTEXTS

\begin{tabular}{|c|c|c|c|c|c|}
\hline No. & Project & Detail tasks & Resource & Achievements & Class hour \\
\hline 1 & $\begin{array}{c}\text { one lamp } \\
\text { controlled in } \\
\text { two terminals }\end{array}$ & $\begin{array}{l}\text { Task 1: recognition of the basic logic-gate circuits } \\
\text { Task 2: simulation \& analysis } \\
\text { Task 3: discussion on logical function of the circuit }\end{array}$ & $\begin{array}{l}\text { PPT, } \\
\text { internet }\end{array}$ & $\begin{array}{c}\text { discussion } \\
\text { conclusion, } \\
\text { simulation result }\end{array}$ & 10 \\
\hline 2 & $\begin{array}{l}\text { change } \\
\text { indicator } \\
\text { circuit of } \\
\text { football court }\end{array}$ & $\begin{array}{l}\text { Task 1: test on the decoders and LEDs; } \\
\text { Task 2: discussion on the scheme of decoding and } \\
\text { display; } \\
\text { Task 3: simulation and analysis of the whole } \\
\text { circuit ; } \\
\text { Task 4: manufacturing and test of the whole circuit }\end{array}$ & $\begin{array}{l}\text { PPT, } \\
\text { internet, } \\
\text { electronic } \\
\text { devices, } \\
\text { welding } \\
\text { tools }\end{array}$ & $\begin{array}{l}\text { design scheme, } \\
\text { simulation result, } \\
\text { hardware circuit } \\
\text { board }\end{array}$ & 16 \\
\hline 3 & $\begin{array}{l}\text { digital one- } \\
\text { way traffic } \\
\text { lights }\end{array}$ & $\begin{array}{l}\text { Task 1: design of pulse signal producing circuit; } \\
\text { Task 2: discussion on the scheme of the counter; } \\
\text { Task 3: simulation and analysis of the whole } \\
\text { circuit; } \\
\text { Task 4: manufacturing and test of the whole circuit }\end{array}$ & $\begin{array}{l}\text { internet, } \\
\text { electronic } \\
\text { devices, } \\
\text { welding } \\
\text { tools }\end{array}$ & $\begin{array}{l}\text { design scheme, } \\
\text { simulation result, } \\
\text { hardware circuit } \\
\text { board }\end{array}$ & 18 \\
\hline 4 & $\begin{array}{l}\text { call system of } \\
\text { the hospital } \\
\text { ward }\end{array}$ & $\begin{array}{l}\text { Task 1: discussion on the objective and } \\
\text { requirements for the project } \\
\text { Task 2: design the system scheme by simulation } \\
\text { individually } \\
\text { Task 3: discussion on design scheme } \\
\text { Task 4: simulation \& implementation of the scheme }\end{array}$ & $\begin{array}{l}\text { internet, } \\
\text { electronic } \\
\text { devices, } \\
\text { welding } \\
\text { tools }\end{array}$ & $\begin{array}{l}\text { design scheme, } \\
\text { simulation result, } \\
\text { hardware circuit } \\
\text { board }\end{array}$ & 20 \\
\hline
\end{tabular}

It is crucial for organizing the teaching contexts to choose the suitable question situations. According to the objective of ability training, we break down the knowledge system of the course of digital electronic technology and re-organize these knowledge points as a series of projects. Every project is a carrier, which concerns with a question situation. The teacher can either use these carriers directly or introduce his/her own new carrier which is relative to the teaching objectives and ability requirements.

The course of Digital Electronic Technology is comprehensive, which embraces applications of the digital electronic devices, analysis of classical digital circuits, usages of simulation software Multisim from the National Instruments Corporation, operations of professional tools and instruments, and etc. Also, it is prior to some other courses related to hardware design.

We reorganize the knowledge points and divide them into four blocks: analysis and application of the basic logic-gate circuits, analysis and application of the comprehensive logical circuits, analysis and application of the sequential logical circuits, and analysis and application of the comprehensive digital circuits [3].

During teaching, we adopt the virtual simulation combining with reality to realize the teaching contexts step by step. We aim to transit students' passive study to active study gradually so that their ability can be improved. So we design four projects such as one lamp controlled in two terminals, the change indicator circuit of football court, digital one-way traffic lights, and call system of the hospital ward [4].

According above four projects, there are three gradual levels for discussion-oriented teaching.

$>$ "Slight discussion"

The first project belongs to the first knowledge block, that is, analysis and application of the basic logic-gate circuits. It embraces a lot of fundamental knowledge, so this knowledge block is mainly taught and analyzed by the teacher. Students are asked to discuss slightly in class. It just makes students experience the discussion mode like a dragonfly skimming the water surface. But it can arouse students' interests in studying the logical circuits in the relaxed and lively situations.

$>$ "Better-off discussion"

The second and the third projects correspond to analysis and applications of the comprehensive logical circuits and the sequential logical circuits. These two knowledge blocks are dealt by the teacher's instructing activity paralleling with students' discussion activity. The percentage of students' discussion activity nearly equals to that of the teacher's instructing activity. Thus, students 
can gradually come into more and more delightful status of discussion-oriented learning led by the teacher's guiding and elicitation.

$>$ "Digestion discussion"

The last project, that is, the call system of the hospital ward, is the comprehensive analysis and application of the integrated digital circuits. This knowledge block is mainly dealt by interactive discussion. Firstly, the teacher describes the question situation and the design goal, and point out the cue of the solution. Secondly, Students are divided into several groups. They try their best to consult related reference material through all possible multimedia channels. Then, they design the preliminary scheme for solving the question situation. Thirdly, students and their teacher discuss the practicability of each scheme together and evaluate advantages and disadvantages on each scheme. Subsequently, students in a group discuss and adjust their own scheme. This procedure could be repeated in many times. Lastly, the scheme is decided and implemented. Through the opening discussion-oriented teaching, it brings the knowledge together with the skills and reaches the union of knowledge, skills and manners. During the teaching activity, the teacher is not only an instructor but also a director, a presenter or a host mastering the whole class. Students are not only the passive anticipators but also the main body of the activity, the active speakers, or the evaluators of the discussion activity. This interactive discussion relaxes the atmosphere in class and enhances the teaching effects as well.

Taking the example of the call system of the hospital ward, we adopt six steps such as "question", “exploration”, “discussion”, "simulation”, “operation” and "evaluation” to complete the research.

- "Question”:

The teacher presents the question situation "the call system of the hospital ward" and gives the technique parameters and requirements of the project.

- "Exploration"

Students and their teacher analyze the task objective and discuss the design ideas together. Then, according to the discussion conclusions, students individually explore the preliminary scheme through looking up related materials.

- "Discussion"

(1) Divide the whole students into several groups. Each group has $4 \sim 5$ students. Students in a group discuss individual's scheme, then choose or combine a suitable and practical scheme.

(2)The whole classmates and the teacher all participate the discussion, compare and evaluate the practicality or performance of each scheme.

(3) According to above discussion conclusions, the scheme is discussed again and adjusted in groups. This procedure repeats in many times. And the discussion process is recorded.

(4) Invite the teacher to join the group discussion and decide the final scheme. Record the discussion process.

- "Simulation"

All members in a group must independently simulate the final scheme by the software Multisim. Furthermore, they should communicate with each other about the simulation result and test the rationality of the scheme again. Also, they can adjust their scheme by simulation.

- "Implementation":

According to the simulation scheme, choose the electronic devices and complete the hardware circuit board by welding. After that, test the board to detect its parameters and the logical function. If the fault is detected, then recover it. The whole process requires the abilities of communication and cooperation.

- "Evaluation"

The evaluation result is composed of three aspects: self-assessment, peer assessment and the teacher assessment. Detailed information is seen as the following in TABLE II. 
TABLE II. EVALUATION RESULT

\begin{tabular}{|l|l|l|l|l|}
\hline Procedure & $\begin{array}{l}\text { Self-assessment } \\
\mathbf{( 2 0 \% )}\end{array}$ & $\begin{array}{l}\text { Peer assessment } \\
\mathbf{( 3 0 \% )}\end{array}$ & $\begin{array}{l}\text { Teacher assessment } \\
\mathbf{( 5 0 \% )}\end{array}$ & Score \\
\hline Consultation (5\%) & & & & \\
\hline Individual scheme (10\%) & & & & \\
\hline Group scheme (15\%) & & & & \\
\hline Discussion (30\%) & & & & \\
\hline Simulation (10\%) & & & & \\
\hline Operation (30\%) & & & & \\
\hline
\end{tabular}

\section{Conclusion}

We have introduced the discussion-oriented teaching mode into the Digital Electronic Technology course for 2 semesters. Compared with the traditional teaching mode, the new mode is not easy for teachers. Contrastly, it requires teachers to pay more attention to the class. Moreover, it challenges more comprehensive abilities to teachers [5]. Teachers should be capable of controlling the whole class. Also teachers should be capable of presenting their questions in suitable way and then leading students into the discussion atmosphere gradually. Teachers should be smart enought to break the ice and arouse students' interests in participation.

The new discussion-oriented teaching mode needs the whole students to join the activity. We found in practice that many students can not change their original study habbits right away and they can't present their ideas correctly. These situations have impacts on the teaching effect. But it becomes more and more popular in students because of its relaxe and interesting class atmosphere. At the same time, it plays an important role in developing students' self-study ability, innovation spirit and presentation skills. Therefore, we are going on exploring the new teaching mode and applying it in our subjects.

\section{Acknowledgment}

In this paper, the research was sponsored by Shanghai Municipal Education Commission and our university.

\section{References}

[1] H.Q.HE, “Reform on Digital Electronic Technique in Higher Vocational Education”, Journal of Shenzhen Polytechnic, Vol.11, No.1, pp.52-57, 2012.

[2] J.H.HU, “The Teaching Method of Researching and Discussing Based on Practical Curriculum in Vocational Education”, Research and exploration in laboratory, Vol.26, No.11, pp.157-159, 2007. [3] Paul Horowitz and Winfield Hill, The art of Electronics 2nd Ed. Cambridge University Press, Cambridge, 1989.

[4] P.K. Lala, Practical Digital Logic Design and Testing. Prentice Hall, 1996.

[5] H.H.ZHENG, “Application of Discussion-oriented teaching in reform”, Journal of Education \& Vocation, Vol.12, No.3, pp. 18-21, 2004. 